\title{
Anti-N-methyl-D-aspartate-receptor encephalitis: diagnosis, optimal management, and challenges
}

This article was published in the following Dove Press journal:

Therapeutics and Clinical Risk Management

I July 2014

Number of times this article has been viewed

\author{
Andrea P Mann' \\ Elena Grebenciucova ${ }^{2}$ \\ Rimas V Lukas² \\ 'Department of Psychiatry \\ and Behavioral Neuroscience, \\ 2Department of Neurology, \\ University of Chicago, Chicago, \\ IL, USA
}

Correspondence: Andrea P Mann Department of Psychiatry and Behavioral Neuroscience, 584I South Maryland Avenue - MC 3077, University of Chicago, Chicago, IL 60637, USA Email andrea.mann7@gmail.com
Objective: Anti- $N$-methyl-D-aspartate-receptor (NMDA-R) encephalitis is a new autoimmune disorder, often paraneoplastic in nature, presenting with complex neuropsychiatric symptoms. Diagnosed serologically, this disorder is often responsive to immunosuppressant treatment. The objective of this review is to educate clinicians on the challenges of diagnosis and management of this disorder.

Materials and methods: A review of the relevant literature on clinical presentation, pathophysiology, and recommended management was conducted using a PubMed search. Examination of the results identified articles published between 2007 and 2014.

Results: The literature highlights the importance of recognizing early common signs and symptoms, which include hallucinations, seizures, altered mental status, and movement disorders, often in the absence of fever. Although the presence of blood and/or cerebrospinal fluid autoantibodies confirms diagnosis, approximately $15 \%$ of patients have only positive cerebrospinal fluid titers. Antibody detection should prompt a search for an underlying teratoma or other underlying neoplasm and the initiation of first-line immunosuppressant therapy: intravenous methylprednisolone, intravenous immunoglobulin, or plasmapheresis, or a combination thereof. Second-line treatment with rituximab or cyclophosphamide should be implemented if no improvement is noted after 10 days. Complications can include behavioral problems (eg, aggression and insomnia), hypoventilation, catatonia, and autonomic instability. Those patients who can be managed outside an intensive care unit and whose tumors are identified and removed typically have better rates of remission and functional outcomes.

Conclusion: There is an increasing need for clinicians of different specialties, including psychiatrists, neurologists, oncologists, neuro-oncologists, immunologists, and intensivists to become familiar with this disorder and its potential complications. Remission can be optimized with prompt detection and aggressive, collaborative treatment within a multidisciplinary team.

Keywords: anti-NMDA receptor, encephalitis, management, treatment, complications, paraneoplastic

\section{Introduction}

Anti- $N$-methyl-D-aspartate-receptor (NMDA-R) encephalitis was first identified in four women with ovarian teratomas who presented with psychiatric symptoms, memory loss, altered levels of consciousness, and central hypoventilation in 2005. 1,2,3 Two years later, the associated antigen was discovered in high concentrations in hippocampal neurons, and was identified as the NMDA-R by Dalmau et al. ${ }^{4}$ This disorder is a type of limbic encephalitis that is typically found in young women with paraneoplastic teratomas. However, the disease has been reported in both sexes, ranging in age from less than a year old to the ninth decade of life, with and without tumors. ${ }^{5}$ Patients can present 
initially with a range of psychiatric symptoms: agitation, paranoia, hallucinations, and aggression. They can later develop dyskinesias, seizures, autonomic instability, decreased level of consciousness, catatonia, and central hypoventilation, requiring ventilator support in an intensive care setting. Despite the risk of fatality, at least $80 \%$ of patients experience significant neurological improvement with tumor removal and immunotherapy with the help of a multidisciplinary team. ${ }^{1}$

Since its discovery, over 300 scientific articles have been published on anti-NMDA-R encephalitis. An autobiographical account of the disorder from a patient's perspective was published recently by a female journalist from New York. ${ }^{6}$ Thus far, much of the literature has focused on neuropsychiatric presentation, the spectrum of symptoms, paraneoplastic aspects, immunological treatment, and longitudinal outcomes. These reports have been primarily targeted for an audience of neurologists and immunologists. Indeed, the multidisciplinary nature of treatment requires knowledge from these experts, as well as those specialized in a variety of other disciplines within medicine, including psychiatry, intensive care, oncology, and rehabilitation medicine. There are very few publications that provide a broad overview of anti-NMDA-R encephalitis; therefore, the objective of this review is to educate clinicians on the challenges of diagnosis and management of this disorder.

\section{Epidemiology}

Encephalitis is a relatively rare syndrome, with most identifiable cases due to an underlying viral infection. Approximately $37 \%-50 \%$ of cases have unknown etiologies. ${ }^{7,8}$ Since development of the NMDA-R assay, some cases of encephalitis of unknown etiology have been able to be reclassified as an autoimmune process. ${ }^{9}$ Over 500 cases have now been reported in the literature. The California Encephalitis Project (CEP) found that for individuals $\leq 30$ years, anti-NMDA-R encephalitis was the most common entity. Within a 3.5-year period, 32 of 761 (4.2\%) cases of encephalitis of uncertain etiology were anti-NMDA-R encephalitis, followed by enterovirus, herpes simplex virus type 1 (HSV-1), varicella zoster virus, and West Nile virus. ${ }^{10}$ In a second study of encephalitis in England, a similar proportion (4.4\%) of cases were determined to be due to antibodies against the NMDA-R. ${ }^{7}$ When considering all cases of encephalitis in individuals 0-87 years old, HSV-1 and acute disseminated encephalomyelitis become the two most common entities, followed by anti-NMDA-R encephalitis. ${ }^{7}$

The median age at symptom onset is estimated to be 21 years; however, cases have been reported in individuals ranging in age from 8 months to 85 years. ${ }^{1}$ Although antibodies have been identified in men, approximately $80 \%$ of cases are female. ${ }^{1}$ Most tumors are found in females roughly between 12 and 45 years of age. ${ }^{1,2,11}$ Detection of teratomas or other tumors is less common in preadolescent children. ${ }^{2,12}$ Male sex has been found to be associated with some of the youngest and oldest cases. In a recent report by the CEP, $78 \%$ of cases in California were white Hispanics and Asian/Pacific Islanders, with $6 \%$ of cases found in white non-Hispanics. ${ }^{10}$ In addition, tumors associated with anti-NMDA-R encephalitis are found more often in Asian and black patients, which suggests a possible genetic risk associated with this paraneoplastic disorder. ${ }^{1,2}$ As more cases are identified, a better understanding of potential risk factors will become clearer.

\section{Neurobiology and pathophysiology}

There is compelling evidence suggesting that this neuropsychiatric disorder is the consequence of immunoglobulin (Ig) $-\mathrm{G}_{1}$ and $\mathrm{IgG}_{3}$ antibodies binding to the GluN1 subunit of the NMDA-R. ${ }^{2,9}$ Although this class of antibody can activate the complement system, deposits of complement have been found only in peripheral teratomas, and not in the brain itself.

In vivo and in vitro studies have shown that antibodies from patients bind selectively to synaptic NMDA-R surface density in animal hippocampal neurons. ${ }^{9,13}$ They cause a significant reversible decrease in NMDA-R clusters, which are dependent on antibody titers. ${ }^{9}$ Based on research by Hughes et $\mathrm{al},{ }^{14}$ the mechanism underlying this process is due to internalization of antibody-capped NMDA-Rs. In patch-clamp studies of excitatory postsynaptic currents in rat hippocampal neurons, antibodies from patients specifically reduced NMDA-R currents. ${ }^{14}$ They did not affect other glutamate receptors, the number of synapses, dendritic structure, or cell survival either.

The NMDA-R is a type of ionotropic glutamate receptor found on neuronal membranes. Although concentrated in the hippocampus, these receptors are also found in many other areas of the brain (eg, cortical and subcortical regions, sensory and association cortices). Glutamate is the primary excitatory neurotransmitter in the brain, and is involved in postsynaptic excitation of neurons and neuronal plasticity. In most hippocampal pathways, NMDA-Rs are involved in synaptic modification, which is an activity-dependent, graded response, also known as long-term potentiation. ${ }^{15}$ The NMDA-R's involvement in spatial learning and long-term potentiation is a key feature of memory formation. A clinical finding consistent with NMDA-R's role in learning and 
memory is the observation that anti-NMDA-R encephalitis patients experience persistent amnesia of their illness. ${ }^{9}$ Over excitation of NMDA-Rs can lead to neurotoxicity, and is thought to be involved in the pathophysiology of several acute brain injuries, including status epilepticus. ${ }^{16}$ Sustained hypofunction of the NMDA-R is thought to underlie the pathophysiology of psychosis, Alzheimer's disease, and now autoimmune encephalitis.

NMDA-R antagonists, like phencyclidine and ketamine, have dose-dependent psychotomimetic effects, similar to those seen in anti-NMDA-R encephalitis. Lower doses of phencyclidine and lower-potency NMDA-R antagonists (eg, ketamine) can replicate early stage NMDA-R encephalitis symptoms: hallucinations, delusions, disorganized and impoverished thought, speech dysfunction, agitation, and emotional lability. Higher doses of NMDA-R antagonists can result in decreased responsiveness, dissociative amnesia, catatonic symptoms, autonomic dysregulation, and even coma. ${ }^{17}$ Observing the parallels between psychosis and druginduced NMDA-R dysfunction prompted development of an NMDA-R hypofunction hypothesis of schizophrenia. ${ }^{18,19}$

This receptor has been the subject of a growing number of studies to understand brain aging, Alzheimer's disease, schizophrenia, depression, and other mental illnesses. ${ }^{16,20,21}$ Antibodies binding to different components of the NMDA-R may be implicated in other disease processes. Steiner et $\mathrm{al}^{22}$ found a small proportion of patients with schizophrenia and major depressive disorder had antibodies directed against the NR1a/NR2b subunit, suggesting that different autoantibodies may be responsible for different disorders of the brain that share similar clinical symptoms, such as problems with learning, memory, and behavior.

If populations develop varied syndromes due to autoantibodies to different NMDA-R epitopes, some people may be predisposed to develop encephalitis, while others may be predisposed to develop psychosis or memory problems. Genetic vulnerability coupled with an antecedent viral infection may predispose some individuals to developing anti-NMDA-R encephalitis. It has been proposed that a viral infection may trigger an inflammatory response that disrupts the blood-brain barrier, allowing autoantibodies to enter the central nervous system. ${ }^{13,23}$ This may subsequently allow antigen-specific $\mathrm{T}$ cells to become involved in intrathecal production of antibodies to NMDA-Rs that bind to subcortical neurons. Laboratory evidence supporting this hypothesis is the finding that cerebrospinal fluid (CSF) lymphocytosis is found early in the disease process, while later-stage CSF contains oligoclonal bands. ${ }^{13}$ However, this immune response is self-limited, because even for patients without tumors, antibody titers gradually decline, correlating with gradual cognitive improvement. ${ }^{24}$ Despite several advances in our understanding of the NMDA-R and clinical manifestations of its associated encephalitis, the underlying immune trigger remains unknown.

\section{Clinical manifestations}

The syndrome typically begins with a prodrome of coldlike symptoms, which can include nausea, vomiting, fever, headache, and fatigue. ${ }^{2,9}$ This is followed by a spectrum of neuropsychiatric sequelae. Within the first month, nearly $90 \%$ of patients experience at least four of eight characteristic features: behavior/cognition problems, memory deficit, speech disorder, seizures, movement disorder, loss of consciousness, autonomic symptoms, and hypoventilation. ${ }^{1}$ Emerging symptoms during the disease course can be loosely organized into early and late stages.

Early stage symptoms typically occur within 2 weeks following the prodrome. ${ }^{2}$ Common features during this period include cognitive dysfunction (eg, confusion, amnesia), psychiatric symptoms (eg, paranoia, hallucinations, agitation, aggression, depression, anxiety, and self-harming behavior), and seizures (typically generalized or complex partial). Initial onset of isolated psychiatric symptoms is rare ${ }^{11}$; however, an estimated $77 \%$ of cases are initially seen by psychiatrists, ${ }^{9}$ and many are misdiagnosed as new-onset schizophrenia or bipolar disorder. ${ }^{11,24-27}$ Psychiatrists should be suspicious for an encephalitic etiology in patients presenting with suddenonset psychiatric symptoms that are not responsive to antipsychotic medication. These acute behavioral changes may be initially accompanied by fluctuating levels of attention and problems with memory (ie, delirium) in the context of subtle neurological abnormalities (eg, brief facial twitching). ${ }^{11}$

Symptom presentation differs slightly across children ( $<12$ years) compared to adolescents and adults. ${ }^{1}$ In children, behavior problems and seizures are most common, and equally likely to appear as an initial symptom. Although seizures can reemerge at any time during the clinical course, their intensity and frequency tends to subside with time. A larger proportion of children also present with movement disorders (eg, orofacial dyskinesias, choreoathetosis) compared to older individuals. In adolescents and adults, most cases initially present with abrupt behavioral or psychiatric problems, such as hallucinations, paranoia, and agitation. It is important to differentiate between complex partial seizures and movement disorders, as both may have similar clinical features. Often, seizures will be relatively short in duration, 
lasting minutes, while movement disorders may have more prolonged or continuous symptomatology. Additionally, seizures may occur during sleep, while movement disorders in general do not. Electroencephalography (EEG), including prolonged video EEG monitoring, may be of value in some cases in differentiating the two groups of clinical symptoms. This differentiation is of particular importance, as the two respond to different therapeutic interventions.

Later-stage symptoms are characterized by decreased responsiveness and consciousness, sleep disturbance, hypoventilation, autonomic instability, and in some cases catatonia. Memory deficits and central hypoventilation are more frequent in adults. Patients can also alternate between an unresponsive state, typical of catatonia, and agitation. ${ }^{24}$

Abnormal movements, which include dyskinesias, choreathetoid movements, dystonic posturing, and abnormal ocular movements, are common, ${ }^{9}$ and can overlap with a couple of shared features of catatonia: posturing and waxy flexibility. Given the NMDA-R-hypofunction model of schizophrenia, ${ }^{28,29}$ and the understanding that catatonia results from $\gamma$-aminobutyric acid (GABA)-ergic dysregulation, ${ }^{30}$ it is not surprising that some movements seen in catatonia associated with schizophrenia resemble aspects of the movement disorder seen in anti-NMDA-R encephalitis. ${ }^{31}$ Delayed treatment resulting in a worsening autoimmune process can result in progression of movement-disorder symptoms, which in some cases can encompass classic catatonia (see Table 1). ${ }^{32}$

Another late-stage symptom, autonomic instability, can result in hypertension or hypotension, bradycardia or tachycardia, hyperthermia, hypersalivation, and urinary incontinence. $^{2}$ Fluctuation between tachycardia and bradycardia interrupted by cardiac pauses has prompted the use of a temporary pacemaker in some patients. ${ }^{33}$ The presence

Table I DSM-5 criteria for catatonia requires the presence of three or more of the following

Catalepsy (ie, passive induction of a posture held against gravity) Waxy flexibility (ie, slight and even resistance to positioning by examiner) Stupor (no psychomotor activity, not actively relating to environment) Agitation, (ie, not influenced by external stimuli)

Mutism (ie, no or very little verbal response)

Negativism (ie, opposing or not responding to instructions or external stimuli)

Posturing (ie, spontaneous and active maintenance of a posture against gravity)

Stereotypes (ie, repetitive, abnormally frequent, non-goal-directed movements)

Grimacing

Echolalia (ie, mimicking another's speech)

Echopraxia (ie, mimicking another's movements)

Abbreviation: DSM, Diagnostic and Statistical Manual of Mental Disorders. of autonomic instability in the context of catatonia raises concern for malignant catatonia. ${ }^{5}$ This has implications for the level of collaborative care required.

\section{Differential diagnosis}

There are several disorders to consider as part of the differential diagnosis. The typical anti-NMDA-R encephalitis patient is a previously healthy young female presenting with acute, severe emotional distress and cognitive disturbance. One may consider acute psychosis, temporal lobe seizures, toxic and metabolic disorders (including drug ingestion), a focal brain lesion, or encephalitides (both viral and autoimmune). Encephalitis is defined as altered mental status in a hospitalized immunocompetent individual at least 6 months of age, who has at least one of the following: focal neurologic findings, seizure, fever, CSF pleocytosis, neuroimaging abnormality, or EEG irregularities. ${ }^{34}$

When considering encephalitides, there are several important tests to obtain for an initial workup. Quickly starting appropriate treatment is crucial for optimizing outcome. Therefore, even before a neurology consultation may be completed, one should consider obtaining serum and CSF for evaluation of viral and autoimmune causes of encephalitis, EEG, and magnetic resonance imaging (MRI) with and without contrast. Although such serum inflammatory markers as C-reactive protein and erythrocyte sedimentation rate are nonspecific for inflammatory processes, they may be helpful in generating a differential.

If the patient presents with a medical history that raises sufficient clinical suspicion, serum, CSF, and respiratory samples can be evaluated for HSV-1, respiratory viruses, and mycoplasma pneumonia. Special attention should be given to cases with relapses of HSV encephalitis or prolonged atypical cases, as recently more data have emerged showing that HSV may be a trigger for synaptic autoimmunity leading to antiNMDA-R encephalitis in a subgroup of patients. Specifically, relapses in HSV encephalitis were investigated due to such atypical features as choreoathetosis in several children. They were found to be HSV-negative by polymerase chain reaction in CSF, but positive for anti-NMDA-R antibody, and subsequently did not respond to antiviral therapy. This subgroup did respond to immunotherapy. ${ }^{35,36}$

Evaluation for arbovirus may be considered in cases exposed to mosquito or tick vectors in warm-weather climates. Blood and CSF, when possible, should be examined for paraneoplastic antibodies, including those targeting surface antigens (NMDA-R, $\alpha$-amino-3-hydroxy5-methyl-4-isoxazolepropionic acid receptor, glycine 
receptor, $\mathrm{GABA}_{\mathrm{B}}-\mathrm{R}$, mGlu-R5, voltage-gated potassium channel [both leucine-rich glioma-inactivated protein 1 and contactin-associated protein-like 2], and voltage-gated calcium channel) and intracellular antigens (gadolinium, amphiphysin, $\mathrm{Hu}, \mathrm{Ma}$, Ma2). Not all of these are included in commercially available paraneoplastic panels, and some may require serum to be sent to the investigational laboratory if suspicion for a paraneoplastic encephalitis is high. CSF cell count, glucose, protein, and oligoclonal bands (present in $25 \%-60 \%$ of cases $)^{9,24}$ can provide supportive evidence of an autoimmune process to help narrow the diagnosis while waiting for results from the antibody tests.

In the early, cortical phase of the disease, CSF lymphocytosis and few oligoclonal bands are typically observed, whereas during the later stage, lymphocytosis can disappear and oligoclonal bands become more prominent. ${ }^{13}$

One should expect to find normal glucose levels, moderate CSF pleocytosis, and protein levels with significantly lower median values in anti-NMDA-R encephalitis than cases of viral etiologies. ${ }^{10}$ There are many general symptoms common to viral encephalitis that make it difficult to distinguish from anti-NMDA-R encephalitis. However, severe headaches and fever are more commonly seen in varicella zoster virus and West Nile virus, whereas seizures, movement disorders, language dysfunction, autonomic instability, hallucinations, and other psychotic symptoms are common in anti-NMDA-R encephalitis. ${ }^{10}$ Seizures in the absence of fever should raise a clinician's suspicion for anti-NMDA-R encephalitis. ${ }^{7}$ Other causes of autoimmune-related encephalopathies include systemic lupus erythematosus cerebritis, antiphospholipid antibody syndrome, Sjögren's syndrome, and Hashimoto's encephalopathy, as well as primary central nervous system and systemic angiitis.

MRI is not sensitive for detection of anti-NMDA-R encephalitis, as only a third of patients show abnormalities. ${ }^{1}$ There is often subtle contrast enhancement in the cerebellar or cerebral cortex, hippocampus, frontobasal and insular areas, and the brain stem. ${ }^{2}$ Changes can appear transiently, and may resemble demyelination. Diffusion tensor imaging sequences appear to detect widespread deficits in white-matter integrity not apparent on standard MRI. Functional MRI has demonstrated decreased resting-state functional connectivity between the hippocampus and other structures. ${ }^{37}$

EEGs have been found to be abnormal in approximately $90 \%$ of cases, and commonly show nonspecific generalized slowing. ${ }^{1}$ However, in approximately $30 \%$ of patients, a relatively unique EEG pattern - extreme delta brush, consisting of $1-3 \mathrm{~Hz}$ rhythmic activity with superimposed $20-30 \mathrm{~Hz}$ rhythmic activity, similar to beta-delta complexes seen in premature infants - has been noted..$^{38}$

A definitive diagnosis is made with detection of antiNMDA-R antibody in the blood or CSF. Brain biopsy usually shows normal tissue or nonspecific inflammatory changes, and should be avoided. ${ }^{2}$ In some patients who have undergone brain biopsy, nonspecific scattered parenchymal T-cell infiltration and perivascular B-cell cuffing was found., ${ }^{9,39}$ For those who undergo serum testing, approximately $15 \%$ of individuals have antibodies detectable only in the CSF. ${ }^{1}$ Antibody titers tend to be higher in those with tumors. Encephalitis in patients without identifiable tumors may be due to microscopic germ-cell teratomas that are not detectable by current imaging technology. ${ }^{2}$ Once antibodies have been detected, further imaging should be obtained to identify any underlying teratoma. Pelvic ultrasound and MRI, as well as whole-body computed tomography and positron emission tomography have been used.

\section{Management}

Once the diagnosis is confirmed with serum or spinal fluid positive for anti-NMDA-R antibodies, treatment should begin promptly. Although several different specialists may be called upon to help in the management of these patients, based on our clinical experience and successful cases described in the literature, the treatment team is best led by a neurologist, preferably with neuro-oncological expertise. In cases of severe hypoventilation requiring respiratory support, an intensive care specialist may lead the team. ${ }^{25,40}$ Video EEG monitoring may help with diagnosis to confirm the presence of both ictal and non-ictal patterns. ${ }^{38,41}$ Psychiatrists may be consulted to help with management of insomnia, aggression, agitation, psychosis, and catatonic features. ${ }^{27}$ Nurses often must work closely with the physician team and a one-to-one sitter to ensure the safety of the patient. Nurses and sitters are often in the best position to observe abrupt, impulsive behavior that is characteristic of this disorder (eg, pulling out IV lines, attempting to elope, and lip biting). Nutritionists, with the help of speech therapists, can make recommendations for adequate caloric intake when altered levels of consciousness and/or dysphagia present. Physical and occupational therapists are able to assess and maximize safe functioning in the acute inpatient setting and during the rehabilitation phase. Frequent multidisciplinary meetings can help facilitate coordination of care. Regular family meetings should provide education, updates on the patient's status, and immediate and intermediate goals of care.

Soon after a diagnosis is confirmed, patients should undergo imaging studies to identify any potentially 
underlying neoplasm, because tumor removal can be curative. Neuropsychiatric symptoms can subside within a month of tumor extraction and immunosuppression. ${ }^{42}$

In order to assess changes in functional level in patients during treatment, the modified Rankin scale has been used. It is a simple clinician-based rating scale of patient disability that can be used repeatedly throughout the course of treatment and recovery. ${ }^{43}$ It has good interobserver agreement. A score of 0-2 out of 5 is considered a good outcome.

First-line immunotherapy should include intravenous (IV) methylprednisolone and IV Ig or plasmapheresis, or a combination of these. Dalmau et $\mathrm{al}^{2}$ report a preference for simultaneous methylprednisolone (1 g/day) and IV Ig ( $0.4 \mathrm{~g} / \mathrm{kg}$ per day) administration for 5 days. Plasmapheresis requires large-bore catheterization, which proves logistically more difficult in uncooperative patients, children, or individuals with autonomic instability. They also outline the most aggressive treatment strategy, suggesting that clinicians switch to second-line immunotherapy if there are no signs of improvement after 10 days.

Second-line treatment includes rituximab and cyclophosphamide. In adults, Dalmau et al recommend rituximab $\left(375 \mathrm{mg} / \mathrm{m}^{2}\right)$ initiation with the first dose of cyclophosphamide $\left(750 \mathrm{mg} / \mathrm{m}^{2}\right){ }^{2}$ Rituximab is continued every week for 4 weeks, while cyclophosphamide is dosed every month until there are signs of significant clinical improvement and evidence of decreased serum and CSF titers. A rheumatology, neuroimmunology, or neuro-oncology specialist with more experience dosing rituximab may prove helpful in providing recommendations on dosing, especially for pediatric cases, and monitoring medication side effects.

For those patients with no detectable tumors, continued immunosuppression with azathioprine or mycophenolate should be considered, as these patients tend to experience relapses of symptoms. It has been recommended that immunosuppression continue for a minimum of 1 year following symptom remission in patients without tumors to prevent relapse. Age- and sex-appropriate screening for teratomas should continue periodically, because there have been reports of ovarian teratomas detected years after initial presentation. Periodic screening for ovarian teratomas in female patients over the age of 12 years with MRI of the abdomen and pelvis every 6 months for 4 years has been recommended, based on surveillance recommendations for other paraneoplastic syndromes. ${ }^{44}$ There are currently no standardized recommendations for patients not meeting these criteria. After a patient has shown significant, sustained improvement, antiepileptic medications can be discontinued.

\section{Prognosis}

Recovery is usually a slow process, often taking many months of rehabilitation with the help of occupational, physical, and speech therapists. Comprehensive inpatient rehabilitation is often needed to help maximize safe functioning, provide accommodations for functional deficits, continue managing residual symptoms, and educate families. ${ }^{45}$ However, some cases continue to have problems with cognition (comprehension, memory, attention, and expression) and motor function (gait, self-care, swallowing). ${ }^{1,45}$ Tumors are typically not detected in children, which likely accounts for poorer reported functional outcomes in this population. ${ }^{46}$ Some individuals have a protracted recovery, requiring years before achieving significant improvement in overall functioning. . $^{1,47}$

Approximately $80 \%$ of patients have a favorable outcome (modified Rankin scale of 0-2) at the 2-year follow-up. ${ }^{1}$ Early immunotherapy and no intensive care unit admission are factors associated with improved long-term outcome. ${ }^{1,13}$ There is a $12 \%$ risk of relapse, which is more frequent in those without detectable tumors. Episodes of relapse tend to be less severe, and tend to occur in patients who were not given immunosuppressant therapy within the first phase of the disorder. There is an estimated $7 \%$ occurrence of mortality at 24 months. ${ }^{1}$

\section{Challenges}

Delayed diagnosis can prolong immunosuppressant initiation and lead to a more severe syndrome, which can result in hypoventilation, coma, or status epilepticus. These severe cases are often treated for extended periods of time in an intensive care unit. ${ }^{24}$

If individuals are thought to have a primarily psychiatric disorder (eg, acute psychosis due to schizophrenia or bipolar disorder), they are often started on antipsychotic medication, which can cause stiffness and movement disorders, such as cogwheel rigidity and akathisia, as side effects. This can confuse the clinical picture, because movement disorders and waxy flexibility associated with catatonia are common symptoms also characteristic of anti-NMDA-R encephalitis.

Another challenge to providing appropriate medical treatment occurs after patients have been given antipsychotic medication during later-stage symptoms. The constellation of muscle rigidity, increased muscle enzymes (ie, creatine phosphokinase), rhabdomyolysis, and autonomic instability are symptoms specific to anti-NMDA-R encephalitis without the presence of antipsychotic medication. However, after dopamine antagonists are given, the clinical picture can become obscured, calling neuroleptic malignant syndrome into question. 
In addition, agitation, mood lability, impulsivity, hallucinations, insomnia, and self-harming behavior (eg, lip biting or skin picking) are common challenges for the treatment team, and often provide an impetus for psychiatric consultation. Because patients may not be able to follow directions or swallow medication, IV, intramuscular, and nasogastric routes should be considered. Dopaminereceptor antagonists have been used for management of aggression, agitation, and hallucinations without significant improvement, and can in fact obscure an already-complex clinical picture. Potent $\mathrm{D}_{2}$ antagonists (eg, haloperidol) must be used judiciously, because they can intensify movement disorders. Some psychiatrists favor low-dose, low-potency atypical antipsychotics (eg, quetiapine) in the evening to help with insomnia and agitation (Dr James Mackenzie, Department of Psychiatry, Northwestern University Feinberg School of Medicine, Chicago, IL, USA, personal communication, August 9, 2013). Several different classes of medications have been tried, including mood stabilizers for emotional lability, benzodiazepines and other sedative hypnotics for insomnia, histaminergic agents (eg, diphenhydramine) for insomnia, and stimulants for hyperactivity and impulsivity. 5,12,26,27

If catatonia develops, IV benzodiazepine can be administered at regular intervals (eg, $2 \mathrm{mg}$ lorazepam every 6 hours). Doses of 20-30 mg of lorazepam per 24-hour period may be required for improvement. Some child psychiatrists have had success with amantadine for treatment of catatonic symptoms (Dr Roshni Koli, Department of Psychiatry, University of Hawaii, Hilo, HI, USA, personal communication, November 20, 2013). The treatment team should watch for signs of worsening, or malignant catatonia, in which patients become unresponsive to increasing doses of benzodiazepines. Malignant catatonia is characterized by abrupt unresponsiveness, muteness, psychomotor changes, fever, and autonomic instability. Death can result from autonomic instability. Malignant catatonia may be difficult to distinguish from neuroleptic malignant syndrome, because both share hyperthermia and rigidity as defining characteristics. However, muscle rigidity in malignant catatonia is characterized by more dystonic posturing, waxy flexibility, and stereotyped repetitive movements. Electroconvulsive therapy (ECT) is the gold standard for treatment of malignant catatonia. In those select cases with this severity of symptoms, ECT has been shown to be successful. Previous reports have shown that seven to eight bilateral ECT treatments over 2-4 weeks have provided symptom remission in catatonia associated with anti-NMDA-R encephalitis. ${ }^{5,48,49}$ For the minority of patients with worsening movement disorders and level of consciousness who fail to respond to first-line therapy, ECT should be considered as an adjunct treatment. In fact, ECT has been shown to upregulate NMDA-Rs in animal models, ${ }^{50}$ which may account for its success in catatonia due to both anti-NMDA-R encephalitis and schizophrenia. Clinicians should remember that directly addressing the underlying autoimmune process is essential for the optimal management of all clinical symptoms of antiNMDA-R encephalitis, including psychiatric sequelae.

\section{Conclusion}

The rapid development of psychiatric symptoms, seizures, altered cognitive function, and disordered movement in a female without fever should raise suspicion for an underlying encephalitic process, and prompt clinicians to pursue further workup. Anti-NMDA-R syndrome is now the second-most common form of autoimmune encephalitis, and should be considered in differential diagnosis for someone with an abrupt alteration in mental status. Once a diagnosis is confirmed, patients should be quickly screened for underlying tumors and placed on immunosuppressant therapy. Most patients experience sustained remission and near-premorbidity functioning with rapid, aggressive, and continued immunosuppressant treatment.

\section{Disclosure}

The authors report no conflicts of interest in this work.

\section{References}

1. Titulaer MJ, McCracken L, Gabilondo I, et al. Treatment and prognostic factors for long-term outcome in patients with anti-NMDA receptor encephalitis: an observational cohort study. Lancet Neurol. 2013;12(2): 157-165.

2. Dalmau J, Lancaster E, Martinez-Hernandez E, Rosenfeld MR, Balice-Gordon R. Clinical experience and laboratory investigations in patients with anti-NMDAR encephalitis. Lancet Neurol. 2011;10(1):63-74.

3. Vitaliani R, Mason W, Ances B, Zwerdling T, Jiang Z, Dalmau J. Paraneoplastic encephalitis, psychiatric symptoms, and hypoventilation in ovarian teratoma. Ann Neurol. 2005;58(4):594-604.

4. Dalmau J, Tüzün E, Wu HY, et al. Paraneoplastic anti-N-methylD-aspartate receptor encephalitis associated with ovarian teratoma. Ann Neurol. 2007;61(1):25-36.

5. Mann A, Machado NM, Liu N, Mazin AH, Silver K, Afzal KI. A multidisciplinary approach to the treatment of anti-NMDAreceptor antibody encephalitis: a case and review of the literature. J Neuropsychiatry Clin Neurosci. 2012;24(2):247-254.

6. Cahalan S. Brain on Fire: My Month of Madness. New York: Simon and Schuster; 2012.

7. Granerod J, Ambrose HE, Davies NW, et al. Causes of encephalitis and differences in their clinical presentations in England: a multicentre, population-based prospective study. Lancet Infect Dis. 2010;10(12): 835-844.

8. Vora NM, Holman RC, Mehal JM, Steiner CA, Blanton J, Sejvar J. Burden of encephalitis-associated hospitalizations in the United States, 1998-2010. Neurology. 2014;82(5):443-451. 
9. Dalmau J, Gleichman AJ, Hughes EG, et al. Anti-NMDA-receptor encephalitis: case series and analysis of the effects of antibodies. Lancet Neurol. 2008;7(12):1091-1098.

10. Gable MS, Sheriff H, Dalmau J, Tilley DH, Glaser CA. The frequency of autoimmune N-methyl-D-aspartate receptor encephalitis surpasses that of individual viral etiologies in young individuals enrolled in the California Encephalitis Project. Clin Infect Dis. 2012;54(7):899-904.

11. Kayser MS, Titulaer MJ, Gresa-Arribas N, Dalmau J. Frequency and characteristics of isolated psychiatric episodes in anti-Nmethyl-d-aspartate receptor encephalitis. JAMA Neurol. 2013;70(9): 1133-1139.

12. Florance NR, Davis RL, Lam C, et al. Anti-N-methyl-D-aspartate receptor (NMDAR) encephalitis in children and adolescents. Ann Neurol. 2009;66(1):11-18.

13. Irani SR, Bera K, Waters $\mathrm{P}$, et al. N-methyl-D-aspartate antibody encephalitis: temporal progression of clinical and paraclinical observations in a predominantly non-paraneoplastic disorder of both sexes. Brain. 2010;133(Pt 6):1655-1667.

14. Hughes EG, Peng X, Gleichman AJ, et al. Cellular and synaptic mechanisms of anti-NMDA receptor encephalitis. J Neurosci. 2010;30(17):5866-5875.

15. Bliss TV, Collingridge GL. A synaptic model of memory: long-term potentiation in the hippocampus. Nature. 1993;361(6407):31-39.

16. Newcomer JW, Farber NB, Olney JW. NMDA receptor function, memory, and brain aging. Dialogues Clin Neurosci. 2000;2(3):219-232.

17. Javitt DC, Zukin SR. Recent advances in the phencyclidine model of schizophrenia. Am J Psychiatry. 1991;148(10):1301-1308.

18. Javitt DC, Zukin SR, Heresco-Levy U, Umbricht D. Has an angel shown the way? Etiological and therapeutic implications of the PCP/NMDA model of schizophrenia. Schizophr Bull. 2012;38(5):958-966.

19. Newcomer JW, Farber NB, Jevtovic-Todorovic V, et al. Ketamineinduced NMDA receptor hypofunction as a model of memory impairment and psychosis. Neuropsychopharmacology. 1999;20(2):106-118.

20. Lin $\mathrm{CH}$, Huang YJ, Lane HY, Tsai GE. NMDA neurotransmission dysfunction in mild cognitive impairment and Alzheimer's disease. Curr Pharm Des. Epub January 9, 2014.

21. Niciu MJ, Ionescu DF, Richards EM, Zarate CA Jr. Glutamate and its receptors in the pathophysiology and treatment of major depressive disorder. J Neural Transm. Epub December 8, 2013.

22. Steiner J, Walter M, Glanz W, et al. Increased prevalence of diverse $\mathrm{N}$-methyl-D-aspartate glutamate receptor antibodies in patients with an initial diagnosis of schizophrenia: specific relevance of $\operatorname{IgG}$ NR1a antibodies for distinction from $\mathrm{N}$-methyl-D-aspartate glutamate receptor encephalitis. JAMA Psychiatry. 2013;70(3):271-278.

23. Hammer C, Stepniak B, Schneider A, et al. Neuropsychiatric disease relevance of circulating anti-NMDA receptor autoantibodies depends on blood-brain barrier integrity. Mol Psychiatry. Epub September 3, 2013.

24. Wandinger KP, Saschenbrecker S, Stoecker W, Dalmau J. Anti-NMDAreceptor encephalitis: a severe, multistage, treatable disorder presenting with psychosis. J Neuroimmunol. 2011;231(1-2):86-91.

25. van de Riet EH, Esseveld MM, Cuypers L, Schieveld JN. Anti-NMDAR encephalitis: a new, severe and challenging enduring entity. Eur Child Adolesc Psychiatry. 2013;22(5):319-323.

26. Chapman MR, Vause HE. Anti-NMDA receptor encephalitis: diagnosis, psychiatric presentation, and treatment. Am J Psychiatry. 2011;168(3): 245-251.

27. Kruse JL, Jeffrey JK, Davis MC, Dearlove J, Ishak WW, Brooks JO 3rd. Anti-N-methyl-d-aspartate receptor encephalitis: a targeted review of clinical presentation, diagnosis, and approaches to psychopharmacologic management. Ann Clin Psychiatry. 2014;26(1):E1-E9.

28. Coyle JT, Tsai G. NMDA receptor function, neuroplasticity, and the pathophysiology of schizophrenia. Int Rev Neurobiol. 2004;59: 491-515.

29. Javitt DC. Glutamate and schizophrenia: phencyclidine, N-methylD-aspartate receptors, and dopamine-glutamate interactions. Int Rev Neurobiol. 2007;78:69-108.
30. Maneta E, Garcia G. Psychiatric manifestations of anti-NMDA receptor encephalitis: neurobiological underpinnings and differential diagnostic implications. Psychosomatics. 2014;55(1):37-44.

31. Kantrowitz JT, Javitt DC. N-methyl-d-aspartate (NMDA) receptor dysfunction or dysregulation: the final common pathway on the road to schizophrenia? Brain Res Bull. 2010;83(3-4):108-121.

32. American Psychiatric Association. Diagnostic and Statistical Manual of Mental Disorders. 5th ed. Washington: American Psychiatric Association; 2013.

33. Millichap JJ, Goldstein JL, Laux LC, Nordli DR Jr, Stack CV, Wainwright MS. Ictal asystole and anti-N-methyl-D-aspartate receptor antibody encephalitis. Pediatrics. 2011;127(3):e781-e786.

34. Gable MS, Gavali S, Radner A, et al. Anti-NMDA receptor encephalitis: report of ten cases and comparison with viral encephalitis. Eur J Clin Microbiol Infect Dis. 2009;28(12):1421-1429.

35. Leypoldt F, Titulaer MJ, Aguilar E, et al. Herpes simplex virus-1 encephalitis can trigger anti-NMDA receptor encephalitis: case report. Neurology. 2013;81(18):1637-1639.

36. Hoftberger R, Armangue T, Leypoldt F, Graus F, Dalmau J. Clinical Neuropathology practice guide 4-2013: post-herpes simplex encephalitis: N-methyl-D-aspartate receptor antibodies are part of the problem. Clin Neuropathol. 2013;32(4):251-254.

37. Finke C, Kopp UA, Scheel M, et al. Functional and structural brain changes in anti-N-methyl-D-aspartate receptor encephalitis. Ann Neurol. Epub May 20, 2013.

38. Schmitt SE, Pargeon K, Frechette ES, Hirsch LJ, Dalmau J, Friedman D. Extreme delta brush: a unique EEG pattern in adults with anti-NMDA receptor encephalitis. Neurology. 2012;79(11):1094-1100.

39. Camdessanche JP, Streichenberger N, Cavillon G, et al. Brain immunohistopathological study in a patient with anti-NMDAR encephalitis. Eur J Neurol. 2011;18(6):929-931.

40. Varvat J, Lafond P, Page Y, Coudrot M, Reynaud-Salard M, Tardy B. Acute psychiatric syndrome leading young patients to ICU: consider anti-NMDA-receptor antibodies. Anaesth Intensive Care. 2010;38(4): 748-750.

41. Nosadini M, Boniver C, Zuliani L, et al. Longitudinal electroencephalographic (EEG) findings in pediatric anti-N-methyl-D-aspartate (antiNMDA) receptor encephalitis: the Padua experience. J Child Neurol. Epub January 5, 2014.

42. Lesher AP, Myers TJ, Tecklenburg F, Streck CJ. Anti-N-methyl-Daspartate receptor encephalitis associated with an ovarian teratoma in an adolescent female. J Pediatr Surg. 2010;45(7):1550-1553.

43. van Swieten JC, Koudstaal PJ, Visser MC, Schouten HJ, van Gijn J. Interobserver agreement for the assessment of handicap in stroke patients. Stroke. 1988;19(5):604-607.

44. Titulaer MJ, Soffietti R, Dalmau J, et al. Screening for tumours in paraneoplastic syndromes: report of an EFNS task force. Eur J Neurol. 2011;18(1):19-e3.

45. Houtrow AJ, Bhandal M, Pratini NR, Davidson L, Neufeld JA. The rehabilitation of children with anti-N-methyl-D-aspartate-receptor encephalitis: a case series. Am J Phys Med Rehabil. 2012;91(5): 435-441.

46. Borlot F, Santos ML, Bandeira M, et al. Anti-N-methyl D-aspartate receptor encephalitis in childhood. J Pediatr (Rio J). 2012;88(3): 275-278.

47. Iizuka T, Yoshii S, Kan S, et al. Reversible brain atrophy in anti-NMDA receptor encephalitis: a long-term observational study. J Neurol. 2010;257(10):1686-1691

48. Braakman HM, Moers-Hornikx VM, Arts BM, Hupperts RM, Nicolai J. Pearls and Oy-sters: electroconvulsive therapy in anti-NMDA receptor encephalitis. Neurology. 2010;75(10):e44-e46.

49. Lee A, Glick DB, Dinwiddie SH. Electroconvulsive therapy in a pediatric patient with malignant catatonia and paraneoplastic limbic encephalitis. JECT. 2006;22(4):267-270.

50. Watkins CJ, Pei Q, Newberry NR. Differential effects of electroconvulsive shock on the glutamate receptor mRNAs for NR2A, NR2B and mGluR5b. Brain Res Mol Brain Res. 1998;61(1-2):108-113. 
Therapeutics and Clinical Risk Management

Dovepress

\section{Publish your work in this journal}

Therapeutics and Clinical Risk Management is an international, peerreviewed journal of clinical therapeutics and risk management, focusing on concise rapid reporting of clinical studies in all therapeutic areas, outcomes, safety, and programs for the effective, safe, and sustained use of medicines. This journal is indexed on PubMed Central, CAS,

Else, Scopus and the Elsevier Bibliographic databases. The manuscript management system is completely online and includes a very quick and fair peer-review system, which is all easy to use. Visit http://www.dovepress.com/testimonials.php to read real quotes from published authors.

Submit your manuscript here: http://www.dovepress.com/therapeutics-and-clinical-risk-management-journal 